\title{
Genome-wide motif predictions of BCARR- box in the amino-acid repressed genes of Lactobacillus helveticus CM4
}

\author{
Naoyuki Yamamoto ${ }^{1,2^{*}}$ (D) and Taketo Wakai ${ }^{3}$
}

\begin{abstract}
Background: A BCARR (branched-chain amino acid responsive repressor) identified in proteolytic gene expressions in Lactobacillus helveticus is considered to negatively control transcriptions by binding to operator sites at the promoter regions in the presence of BCAAs. However, the distributions and regulatory potential of the BCARR in all genes repressed by BCAAs in $C M 4$ remains unclear.

Results: A genome-wide search for the BCARR-box was conducted to clarify the contribution of BCARR in the regulation of amino acid metabolism in L. helveticus CM4. Among all 2174 genes of CM4, 390 genes repressed by amino acids were selected for the search of the BCARR-box. The annotated 33 genes among the 67 predicted BCARR-boxes were mainly linked to amino acid metabolism. The BCARR-boxes were mainly located adjacent to the -35 sequence of the promoter; however, the repressive effects in different locations were similar. Notably, the consensus BCARR-box motif, 5'-A1A2A3A4 A5W6N7N8N9W10T11T12W13T14T15-3', observed in highly repressed genes, revealed more frequent A-T base pairing and a lower free energy than that in lowly repressed genes. A MEME analysis also supported the lower frequency of T at positions 12, 14, 13 and 15 in the BCARR-box sequence of the lowly repressed gene group. These results reveal that genes with a more stable palindromic structure might be preferable targets for BCARR binding and result in higher repressions in the target gene expressions.
\end{abstract}

Conclusions: Our genome-wide search revealed the involvement of the proteolytic system, transporter system and some transcriptional regulator systems in BCARR-box regulation in L. helveticus CM4.

Keywords: BCARR, Lactobacillus helveticus, Genome-wide search, BCARR-box, MEME analysis, Palindromic structure

\section{Background}

The proteolytic system of lactic acid bacteria is crucial for cell growth in milk and important for the acceleration of ripening in cheesemaking and rapid yogurt manufacturing. The proteolytic system is activated at the beginning of fermentation to release peptides and amino acids for cell growth because of limited nitrogen sources in milk, but is negatively controlled by accumulated amino acids and peptides at the late phase of cell growth $[1,2]$.

\footnotetext{
* Correspondence: n-yamamoto@bio.titech.ac.jp

${ }^{1}$ School of Life Science and Technology, Tokyo Institute of Technology,

4259-J3-8, Nagatsuta-cho, Midori-ku, Yokohama, Kanagawa 226-8501, Japan

${ }^{2}$ Research and Development Center, Asahi Group Holdings Ltd., 11-10,

5-chome, Fuchinobe, Chuo-ku, Sagamihara-shi, Kanagawa 252-0206, Japan

Full list of author information is available at the end of the article
}

Generally, lactobacilli have stronger proteolytic activities and can release higher amounts of peptides and amino acids in fermented milk compared with lactococci [3]. Among Lactobacillus species, Lactobacillus helveticus has the highest proteolytic activity and can release antihypertensive peptides from casein during the milk fermentation process [3-6]. L. helveticus CM4 with the highest proteolytic activity can release the highest amount of these peptides [7, 8]. However, the production of the antihypertensive peptides by $L$. helveticus CM4 was repressed by amino acids that accumulated in fermented milk because of the down-regulation of genes, such as pepO2, pepCE and pepE, that most likely encode enzymes involved in the processing of active peptides $[7,9]$. A novel type of regulator protein, a cystathionine $\beta$-synthase (CBS) domain protein involved in the regulation of the proteolytic system, 
was successfully identified in a previous study [10]. The CBS domain protein binds to a specific DNA sequence present at the promoter regions of the repressed proteolytic genes in response to intracellular BCAAs [10]. From a comparative sequence analysis of the promoter regions of the proteolytic genes, a gel shift assay and a footprinting analysis, a palindromic AT-rich motif, 5'-AAAAANNCTWTTATT-3', was predicted as the consensus DNA motif for the branched chain amino acid responsive repressor (BCARR) protein binding box (BCARR-box). Therefore, the consensus DNA motif is thought to exist in many genes repressed by amino acids including those of the proteolytic enzymes of CM4 [9], but the contributions of BCARR via binding to the BCARR-box in the repressed genes of CM4 are unclear. In Lactococcus lactis and Bacillus subtilis most of the proteolytic genes are regulated by the CodY protein in response to branched chain amino acids (BCAAs) [1, 11-14]. CodY is activated by binding to accumulated BCAAs in the medium, which increases the affinity to its operator site, the $\operatorname{Cod} Y$ protein binding box (CodY-box) [11-14]. However, no CodY and no regulatory system of the proteolytic enzyme have been reported.

Genome-wide search is a powerful tool to understand the contribution of the regulatory system in specific gene expressions in response to some metabolites [15-19]. In the present study, we searched the BCARR-box previously predicted from six kinds of proteolytic genes which were down-regulated in response to amino acids in CM4 [10]. Then, we characterized the structural features of the BCARRbox, palindromic pair, free energy and location from the promoter, to determine the BCARR-driven repressed effect. We also investigated the impact of the BCARR system on amino acid metabolism, which plays a crucial role in cell growth in milk and other metabolism throughout the selection of the downregulated genes by amino acids.

\section{Results}

\section{Distribution of the repressed genes in the whole CM4} genome

Strategic steps to determine the contribution of BCARR on the regulation of specific gene expressions by amino acids in L. helveticus CM4 and the brief outcomes obtained at each step are illustrated in Fig. 1. In the genome-wide transcriptomic analysis, 390 genes of $L$. helveticus CM4 repressed over $30 \%$ at $0.5 \mathrm{~h}$ after the addition of peptides in fermented milk were observed (Additional file 1: Table S1). Various kinds of genes, such as protease, transporter, nuclease and regulatory protein genes, were repressed (detailed in Table S1). Among the 390 repressed genes, 185 genes (47.4\%) encoded putative and unknown proteins. To visualize the genome-wide distributions of repressive gene expressions in L. helveticus CM4, the locations of the repressed genes from the origin of the CM4 genome and the repressive effects by peptides are illustrated in Fig. 2. Various genes with different repressive effects and different locations were positioned in the whole genome (Fig. 2b). Notably, highly repressed genes were located mainly in four large

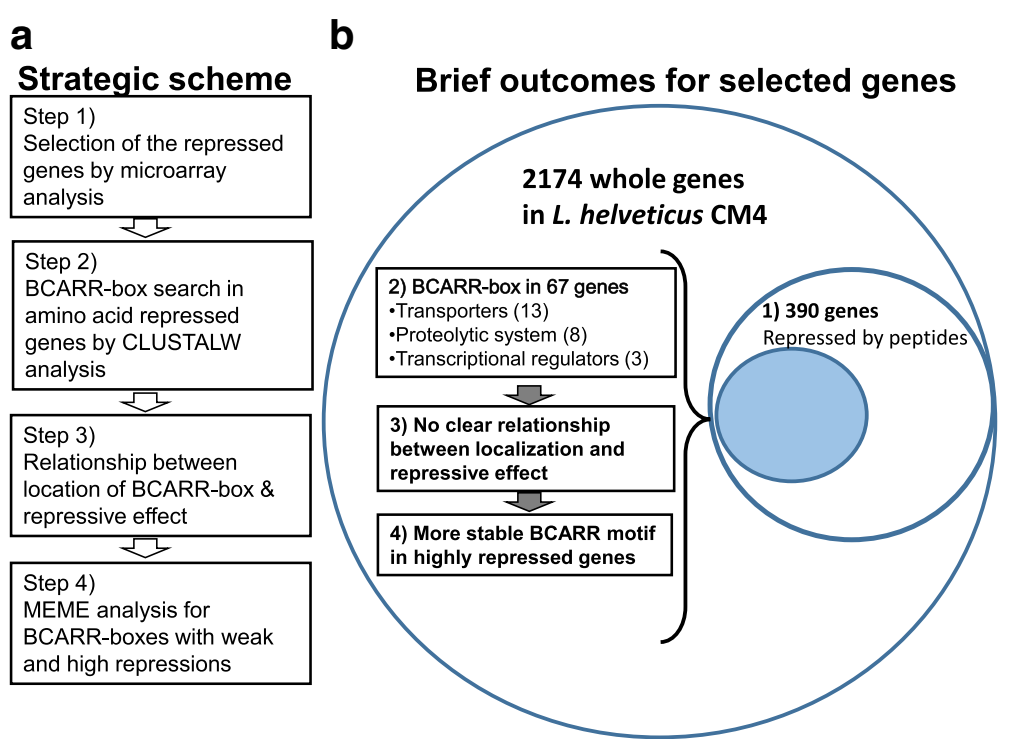

Fig. 1 Strategic workflow of the BCARR motif search and analysis (a) and brief outcomes (b). a Four-step analytical process from a motif search in the repressed genes (Step 1) to a motif analysis for repressive effects (Step 4). b Brief outcomes of each workflow step are summarized 


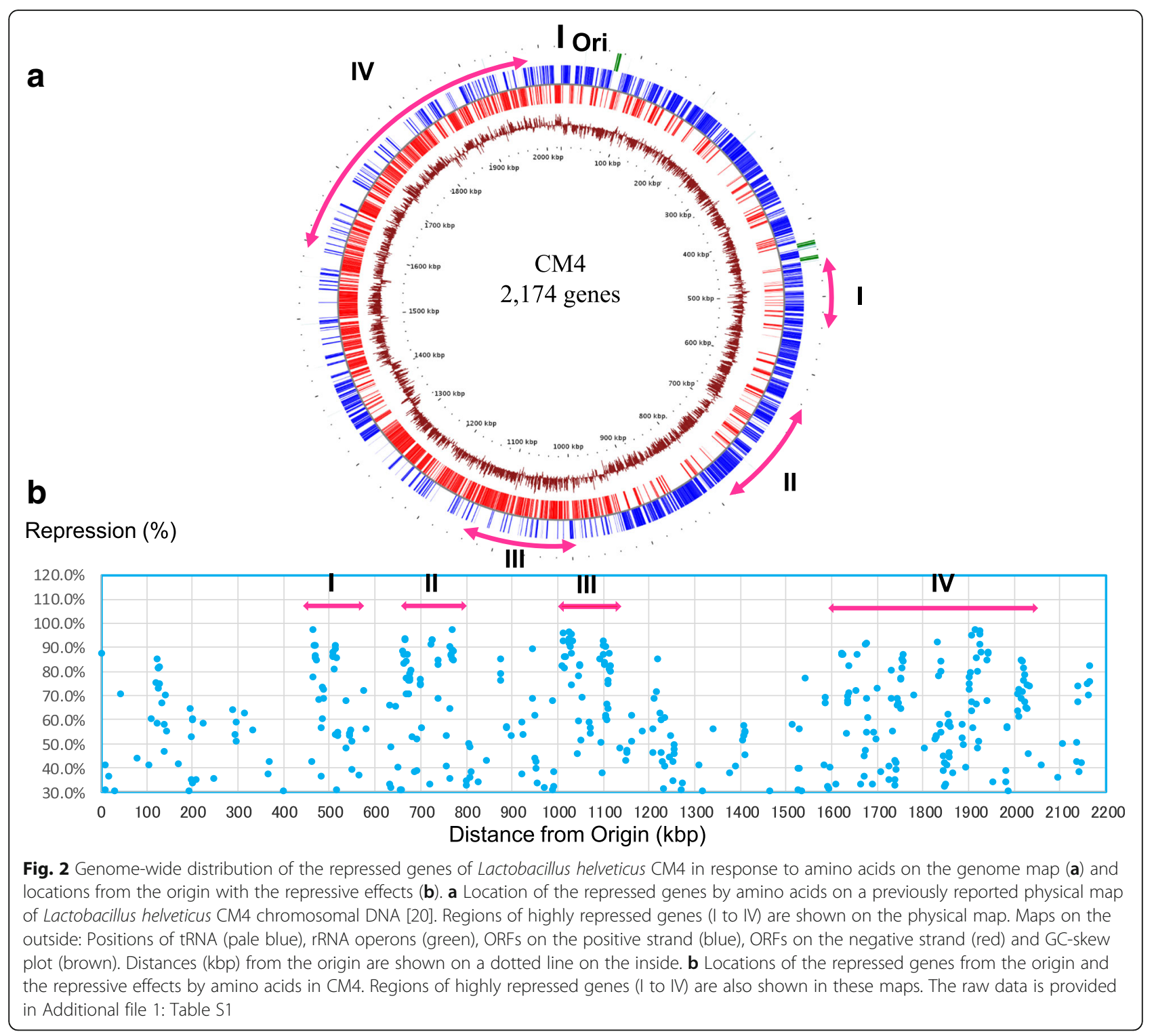

regions (from I to IV in Fig. 2b) and in the previously reported whole genome of L. helveticus CM4 (Fig. 2a) [20].

\section{Prediction of BCARR-box in repressed genes}

As the preliminary study for whole genes, the genomewide survey focused on the 390 genes down-regulated by amino acids. The homologue for an AT-rich palindromic motif, 5'- AAAAANNCTWTTATT -3', predicted as the consensus DNA motif from 6 proteolytic genes in a previous study [10], was surveyed in promoter regions at -300 to $250 \mathrm{bp}$ from the -35 sequence of the promoter region in 390 repressed genes by multiple sequence alignment with a CLUSTALW analysis (http:// www.genome.jp/tools-bin/clustalw). In all, 67 kinds of predicted BCAA-boxes were found in the repressed genes at the promoter regions (Table 1). Corresponding genes, the observed BCARR-box sequence, distances from the -35 sequence of the promoter and the repressive effects by peptides are listed in Table 1 . Strands with an observed BCARR-box and the Waterman-Eggert score analyzed by LALIGN analysis (http://www.ch.embnet.org/software/LALIGN_form.html) are also listed in Table 1. There were no significant differences in the repressive effects of BCARR-boxes located between plus and minus strands. All six proteolytic genes had BCARR-box sequences, but only pepO2, pepD, pepC2 and $d p p D$ genes with repressive effects of $93.0 \%, 89.0 \%$, $68.0 \%$ and $34.0 \%$, respectively, are listed in Table 1; pep $V$ and pepO genes showed lower repressive effects $(27 \%$ and $25 \%$, respectively). 
Table 1 BCARR-boxes observed in promoter regions of specific genes and repressed gene expression in presence of peptides

\begin{tabular}{|c|c|c|c|c|c|c|c|c|}
\hline No & ORF No & $\begin{array}{l}\text { Repression } \\
(\%)\end{array}$ & Strand & ${ }^{a}$ Score & $\begin{array}{l}\text { Location } \\
\text { (bp) }\end{array}$ & Gene & Function & $\begin{array}{l}\text { BCARR-box } \\
\text { sequence }\end{array}$ \\
\hline 1 & 464 & 97.0 & - & 35 & -11 & dapF & Diaminopimelate epimerase & AAAATCACTITITA \\
\hline 2 & 1025 & 97.0 & + & 46 & 254 & paaD & Predicted metal-sulfur biosynthetic enzyme & AAAAATGATATTATC \\
\hline 3 & 1029 & 95.0 & + & 56 & 7 & hisM & ABC-type amino acid transportor & AATAAGACTATTATT \\
\hline 4 & 724 & 93.0 & + & 60 & 87 & pepO2 & Neutral endopeptidase & AAAAAATGCTIITAT \\
\hline 5 & 726 & 93.0 & + & 37 & -120 & potE & Amino acid transporters & AAAAAATCATGTTTT \\
\hline 6 & 1032 & 93.0 & + & 37 & -229 & $d d p A$ & ABC-type dipeptide transport system & AAAATTCTAAAATAT \\
\hline 7 & 765 & 91.0 & - & 33 & 116 & $\operatorname{himM}$ & ABC-type amino acid transporter & AAAAGTATTGTCTTT \\
\hline 8 & 769 & 91.0 & + & 45 & -116 & putative & unknown & AAAAAATCTATTITT \\
\hline 9 & 1099 & 91.0 & - & 37 & -19 & med & Uncharacterized ABC-type transport system & GAAAATAATGTTCTT \\
\hline 10 & 1104 & 91.0 & + & 42 & 150 & putative & unknown & AAAAAAGCCATTCTT \\
\hline 11 & 513 & 90.0 & + & 42 & 24 & $n / p A$ & ABC-type metal ion transport & AGAAATACAATTATT \\
\hline 12 & 661 & 89.0 & + & 37 & -16 & pepD & Di- and tripeptidases & AATAGACTITITTAT \\
\hline 13 & 1113 & 87.0 & + & 42 & 41 & purk & Phosphoribosylaminoimidazole carboxylase & AAAATACCTTGTATT \\
\hline 14 & 1621 & 87.0 & - & 33 & 92 & & Uncharacterized conserved protein & AATACAAGATATTGT \\
\hline 15 & 670 & 86.0 & - & 33 & -11 & putative & unknown & AGAAATAGATTITIT \\
\hline 16 & 738 & 85.0 & + & 35 & 42 & putative & unknown & AAAGTAAGCGTITA \\
\hline 17 & 1219 & 85.0 & + & 46 & 35 & prtH, prtP & Protease P\&H & AAAAAATTAAATGTA \\
\hline 18 & 123 & 85.0 & - & 38 & -15 & putative & unknown & ACAAAAATTATTCTT \\
\hline 19 & 1102 & 84.0 & + & 48 & -254 & putative & unknown & TAAAAAAATATTATT \\
\hline 20 & 737 & 83.0 & - & 36 & 74 & hpt & Hypoxanthine-guanine phosphoribosyltransferase & TGAAAAAGTATTATT \\
\hline 21 & 1543 & 77.0 & - & 34 & -104 & guaA & GMP synthase & AACAAGAACTTITTG \\
\hline 22 & 129 & 75.0 & + & 45 & -14 & putative & unknown & AAAAATCCGTTIITI \\
\hline 23 & 1030 & 74.0 & + & 56 & -47 & putative & unknown & AATAATAGTCTTATT \\
\hline 24 & 576 & 72.0 & - & 36 & -135 & potE & Amino acid transporters & GAAGAATACTCTTTG \\
\hline 25 & 1216 & 72.0 & - & 55 & -29 & putative & unknown & AATAAAAGGTIITA \\
\hline 26 & 1634 & 70.0 & + & 47 & -218 & & ABC-type transportor & AAAAAAACTTTCCTA \\
\hline 27 & 1586 & 69.0 & + & 35 & -14 & guab & IMP dehydrogenase & AACAAGTCCTITITा \\
\hline 28 & 1212 & 69.0 & + & 51 & 64 & pepN2 & Aminopeptidase N2 & AGAACAACACTITAA \\
\hline 29 & 1541 & 68.0 & + & 33 & -90 & putative & unknown & AACAAAACGATCATT \\
\hline 30 & 536 & 68.0 & + & 46 & -67 & pepC2 & Aminopeptidase C & AAAATGCCAATTATT \\
\hline 31 & 1585 & 67.0 & + & 38 & -3 & pepE & Aminopeptidase C & GAACCCGCTTTTATT \\
\hline 32 & 632 & 66.0 & - & 46 & 2 & putative & unknown & AAAAAGTCCAATCTT \\
\hline 33 & 646 & 65.0 & + & 40 & -89 & putative & unknown & AAACGGACAACCTTI \\
\hline 34 & 1162 & 62.0 & - & 42 & -135 & baes & Signal transduction histidine kinase & AATTAAAGGTTTTAT \\
\hline 35 & 950 & 62.0 & + & 44 & 10 & $d d p A$ & ABC-type dipeptide transportor & AAAACATGGTATTAT \\
\hline 36 & 668 & 62.0 & - & 37 & -21 & putative & unknown & AAAAAGCAGCTTAGT \\
\hline 37 & 691 & 59.0 & + & 31 & -177 & lytT & Response regulator & AAAATCTCGCTITIT \\
\hline 38 & 665 & 59.0 & - & 33 & -90 & putative & unknown & AAATATGATATTTTT \\
\hline 39 & 296 & 59.0 & + & 33 & -46 & uup & ATPase components & AAAAAGTITTAATTA \\
\hline 40 & 1070 & 59.0 & - & 46 & 60 & putative & unknown & AATAACACTGTITIT \\
\hline 41 & 1514 & 58.0 & - & 38 & -29 & & GAF domain-containing protein & AATCAAACTTITITC \\
\hline 42 & 701 & 57.0 & - & 37 & -30 & & Uncharacterized conserved protein & GAGAAAAGGTTGTT \\
\hline 43 & 1529 & 56.0 & - & 40 & -89 & & FOG: CBS domain-containing protein & AAGAGATGCTITITT \\
\hline
\end{tabular}


Table 1 BCARR-boxes observed in promoter regions of specific genes and repressed gene expression in presence of peptides (Continued)

\begin{tabular}{|c|c|c|c|c|c|c|c|c|}
\hline No & ORF No & $\begin{array}{l}\text { Repression } \\
(\%)\end{array}$ & Strand & a Score & $\begin{array}{l}\text { Location } \\
\text { (bp) }\end{array}$ & Gene & Function & $\begin{array}{l}\text { BCARR-box } \\
\text { sequence }\end{array}$ \\
\hline 44 & 1340 & 56.0 & - & 46 & 39 & pepQ & Xaa-Pro aminopeptidase & AAAAAGAGGCTATTT \\
\hline 45 & 579 & 56.0 & + & 42 & 125 & uvrC & Nuclease subunit & AAAAACCGGGCTGTT \\
\hline 46 & 518 & 55.0 & + & 46 & -29 & putative & unknown & AAAAAAACAATTATA \\
\hline 47 & 755 & 53.0 & - & 39 & 99 & folB & Dihydroneopterin aldolase & AATACGAGGAGTIT \\
\hline 48 & 1051 & 52.0 & + & 40 & 49 & putative & unknown & AATCAATGTATTATT \\
\hline 49 & 1406 & 51.0 & - & 49 & -51 & fatA & Acyl-ACP thioesterase & AATATAAGTCCTITT \\
\hline 50 & 806 & 50.0 & + & 57 & 64 & putative & unknown & AAAAGAAGCTTGTIT \\
\hline 51 & 807 & 49.0 & + & 40 & 27 & putative & unknown & AACAATAGAATTATA \\
\hline 52 & 537 & 48.0 & + & 38 & -1 & citT & Di- and tricarboxylate transporters & AAAAATAACTTTATT \\
\hline 53 & 1208 & 47.0 & - & 34 & 64 & $h f \mid C$ & Membrane protease subunits & AACAACAGGACTTTA \\
\hline 54 & 1151 & 46.0 & + & 43 & -122 & putative & unknown & AAAAAATTITITTGT \\
\hline 55 & 1254 & 46.0 & + & 49 & 95 & putative & unknown & AAAATAACTATTAAT \\
\hline 56 & 669 & 44.0 & - & 34 & -222 & putative & unknown & ATGAAATCGCTTATT \\
\hline 57 & 1530 & 40.0 & + & 42 & 149 & putative & unknown & AAAAAAGCTTTGCTT \\
\hline 58 & 921 & 38.0 & + & 44 & -12 & putative & unknown & AAAACATCTITITTG \\
\hline 59 & 763 & 35.0 & + & 35 & 55 & putative & unknown & AAAAATGCTTGACTT \\
\hline 60 & 201 & 34.0 & + & 36 & 109 & deoR & Transcriptional regulator & AAAAATACATTGTTA \\
\hline 61 & 825 & 34.0 & - & 47 & -8 & & Uncharacterized protein & ATTAATAGGTTTCT \\
\hline 62 & 954 & 34.0 & + & 49 & 59 & $d p p D$ & ABC-type dipeptide transportor & AAAAAAGCTATAAAT \\
\hline 63 & 1593 & 32.0 & + & 46 & 124 & lytR & Transcriptional regulator & AAAAAACGTCATATT \\
\hline 64 & 635 & 32.0 & + & 51 & -19 & mdlB. cydC, sunT & ATPase and permease components & AAAAACACTTTAATT \\
\hline 65 & 1590 & 32.0 & + & 40 & -29 & putative & unknown & AAAACAGTTTCTTA \\
\hline 66 & 655 & 31.0 & + & 41 & 167 & putative & unknown & AAAAAACGTTTTAGC \\
\hline 67 & 1535 & 30.0 & - & 36 & 114 & putative & unknown & AAAAGTAGTTITCAT \\
\hline
\end{tabular}

a Waterman-Eggert score by LALIGN analysis

\section{Predicted genes with a BCARR-box}

To understand the role of the BCARR in the regulatory system by amino acids, annotated genes with observed BCARR-boxes (Table 1) are summarized in Fig. 3. Among the 67 predicted BCARR-boxes in the promoter regions of the 390 repressed genes, 34 genes were uncharacterized or non-annotated genes listed in Table 1. Half of the annotated 33 genes were linked to amino acid metabolism, such as transporters, proteolytic system and purine synthesis. Nine genes $(\operatorname{pot} E, \operatorname{ddp} A, \operatorname{him} M$, hisM, potE, $d p p D$, sunT, $m d l B$ and $h f l C$ ) were transporter genes. Nine genes (pepO, pepO2, pepE, pepV, pepQ, pepC2, pepN2, prtHEP and pepD) (reviewed in ref. [7]) were proteolytic enzymes. $L y t T$, lytR and $d e o R$ were regulator genes (see Fig. 3). The guaA and guaB genes for purine synthesis [21] may have a link to amino acid metabolism.

Changes of transcriptional regulators by amino acids, such as $l y t L, l y t R$ and $d e o R$, are of interest because these regulators may impact many gene expressions indirectly through BCARR action. The gene products of transcriptional regulators $l y t L$ and $l y t R$ have been suggested to influence alaD gene expression [22]. DeoR, which is widely present in bacteria and acts as a repressor in sugar metabolism [23], may have an indirect effect on sugar metabolism. Various transporter genes have BCARR-motifs at the promoter regions. The sunT gene product has been suggested to function as an antibiotic transporter with a protease domain $[24,25]$. The $m d l B$ gene product also has a protease domain and is likely involved in multidrug transport and bacteriocin export [26]. The $h f l C$ product also has a protease domain and is involved in protein secretion [27]. The $c y d C$ gene product co-expressed with the $c y d D$ gene in E. coli showed ATPase-like activity [28]. PrtD is one of the ATP binding cassette components with low ATPase activity involved in the protease secretion system [29]. CitT is a component of the twocomponent system that plays a crucial role in citrate utilization [30]. 


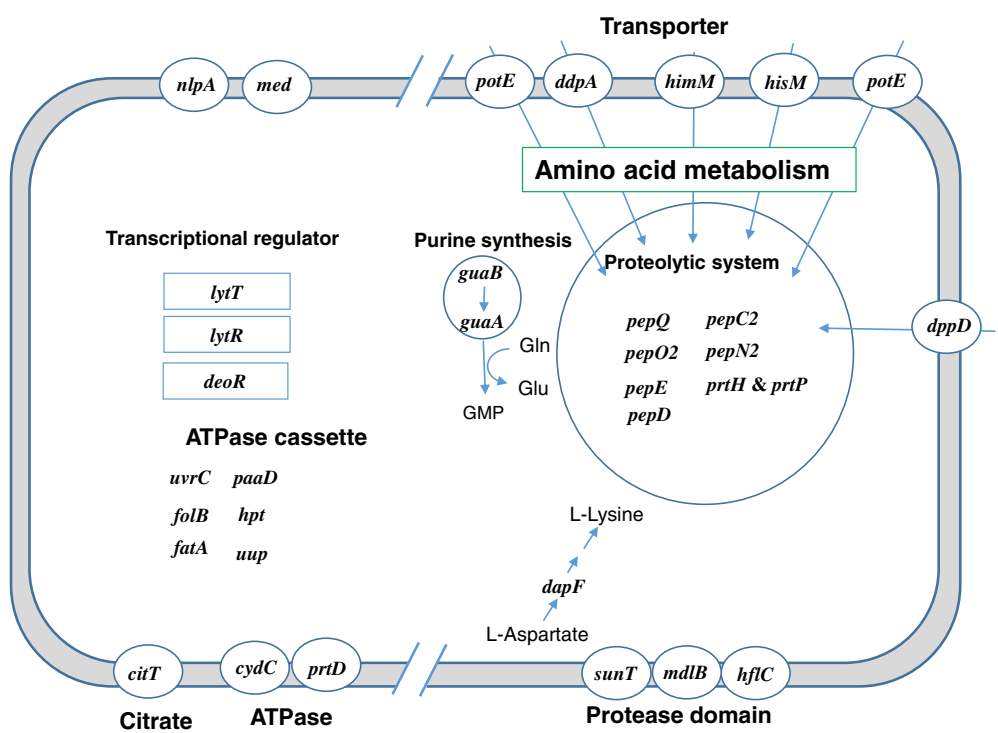

Fig. 3 Down-regulated genes with BCARR-box sequences at the promoter regions in Lactobacillus helveticus CM4. Genes suggested to be involved in amino acid metabolism, the proteolytic system including related transporters and membrane proteases are shown at the right with linked arrows

Localization and the repressive effects of the BCARR-box To understand how the location of the BCARR-box at the promoter regions could interfere with RNA polymerase-promoter binding and the transcriptional activity of the underlying gene, the distance of the predicted boxes from the origin of the CM4 genome and the repressive effects are summarized in Fig. 4. Most of the BCARRboxes were present between -120 to $+150 \mathrm{bp}$ from the
-35 sequence of the promoter, and the boxes were most frequently observed at $0 \mathrm{bp}$ (-30 to $0 \mathrm{bp})$. Unexpectedly, the average repressive effects of each box with different locations at the promoter regions were almost similar (Fig. 4). This result indicates that a wide promoter region, not the more frequent BCARR-box adjacent to the -35 sequence, might be sufficient to express the repressive effects on the transcription.

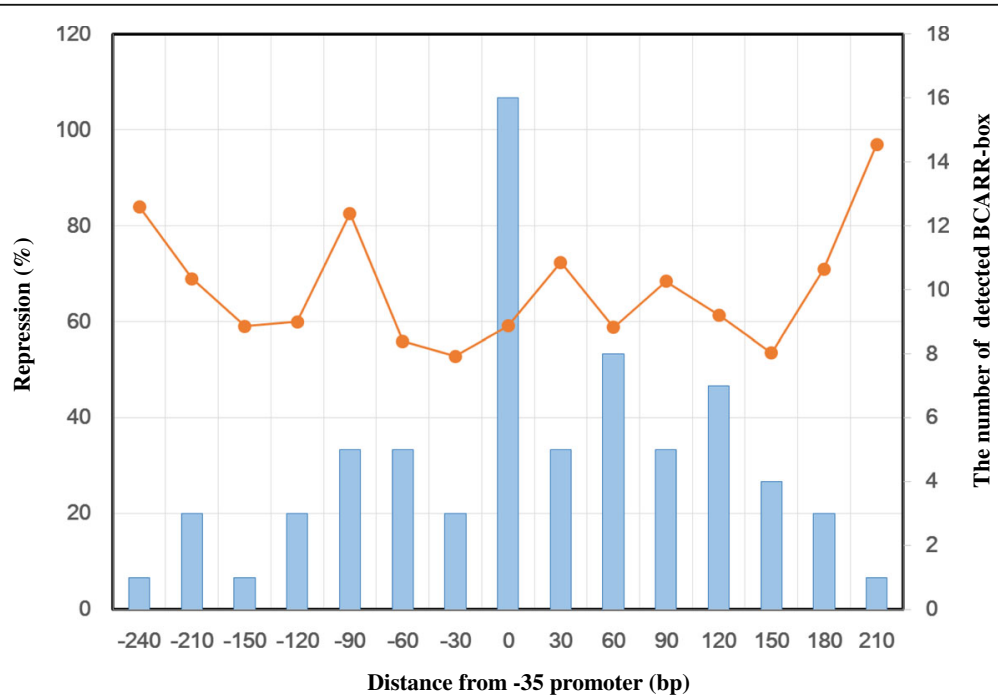

Fig. 4 The number of predicted BCARR-boxes and the average repressive activities with different locations. Data collected from predicted motifs located in each $30 \mathrm{bp}$ long sequence were used to calculate the average repressive effects (indicated by a line). The number of detected BCARRboxes is shown by a column. The locations indicated are the distances (bp) from the -35 bp sequence of the promoter: -240 (from -269 to $-240 \mathrm{bp}$ ), -210 (from -239 to $-210 \mathrm{bp}$ ), -150 (from -179 to $-150 \mathrm{bp}$ ), -120 (from -149 to $-120 \mathrm{bp}$ ), -90 (from -119 to $-90 \mathrm{bp}$ ), -60 (from -89 to $-60 \mathrm{bp}$ ), -30 (from -59 to $-30 \mathrm{bp}$ ), 0 (from -29 to $0 \mathrm{bp}$ ), 30 (from 1 to $30 \mathrm{bp}$ ), from 60 (from 31 to $60 \mathrm{bp}$ ), 90 (61 to $90 \mathrm{bp}$ ), 120 (from 91 to $120 \mathrm{bp}$ ), 150 (from 121 to $150 \mathrm{bp}$ ), 180 (from 151 to $180 \mathrm{bp}$ ) and 210 (from 181 to $210 \mathrm{bp}$ ) 
Comparison of highly and lowly repressive box sequences No clear differences in average repressive effects that were dependent on the location of BCARR-boxes in the promoter regions were observed if the regions were limited from -300 to $+250 \mathrm{bp}$ from the -35 sequence (Fig. 4). Therefore, each location of the BCARR-box from the -35 sequence of the promoter and the repressive effects are illustrated in Fig. 5. BCARR-boxes were most frequently present at -120 to $+150 \mathrm{bp}$ from the $-35 \mathrm{bp}$ sequence of the promoter. Thus, BCARR-boxes from -120 to +150 bp with high and lowly repressions were selected for structural feature analysis. As listed in Table 2, the repressive effect for Group A shown by green box with repression over $80 \%$ was $88.9 \pm 3.9 \%$, and that of the low repressive Group B with repression less than $50 \%$ was $36.3 \pm 3.8 \%$. The repressive effect for Group A was significantly higher than that for Group B $(P<0.001)$.

To determine the reason for the different repressive effects in the two groups, the number of base pairs in the palindromic sequence and the free energy for each BCARR-box were analyzed (Table 2). The average number of palindromic pairs was significantly higher in Group A $(4.1 \pm 0.8)$ than in Group B $(3.3 \pm 1.0)(P<0.05)$ because of fewer Ts at positions 12, 13, 14 and 15 in Group B than in Group A. The free energy represented as the $\Delta G$ value for a BCARR-box was evaluated by $M$ fold analysis (http://unafold.rna.albany.edu/?q=mfold/ DNA-Folding-Form) and compared among the two groups. As for the $\Delta G$ analysis, all BCARR-box sequences in Group A were available in the M-fold tool, but approximately half of the sequences in Group B were not (Table 2) As expected from the number of base pairs shown in Table 2, the $\Delta G$ values, which reflect the stability of the palindromic pair, were significantly lower in Group A $(-0.25 \pm 1.67)$ than in Group B $(0.85 \pm 0.90)$ $(P<0.05)$. The above findings revealed that the predicted palindromic sequence might be more stable for Group A than for Group B.

For further consideration of the different repressive effects between the 2 groups, the predicted motifs of the BCARR-box from 18 sequences of Group A and 18 sequences of Group B were compared by MEME analysis. As shown in Fig. 6, the structural features of the motifs for Group A were relatively conserved AT-rich palindromic sequences, but Group B contained slightly fewer Ts than Group A at positions 12 (67\%), 13 (33\%), 14 $(67 \%)$ and $15(67 \%)$. This result suggests that fewer Ts at positions 12, 13, 14 and 15 in the BCARR-box of Group $B$ might make a less stable palindromic structure than that of Group A. A more stable palindromic structure of the BCARR-box in Group A genes than in Group B might have the advantage of conferring a higher affinity to the BCARR protein and, thus, a higher repressive effect. Considering the above results, the repressive effects of amino acids through the BCARR system might be more dependent on an AT-rich stable palindromic structure than on the location within the promoter region.

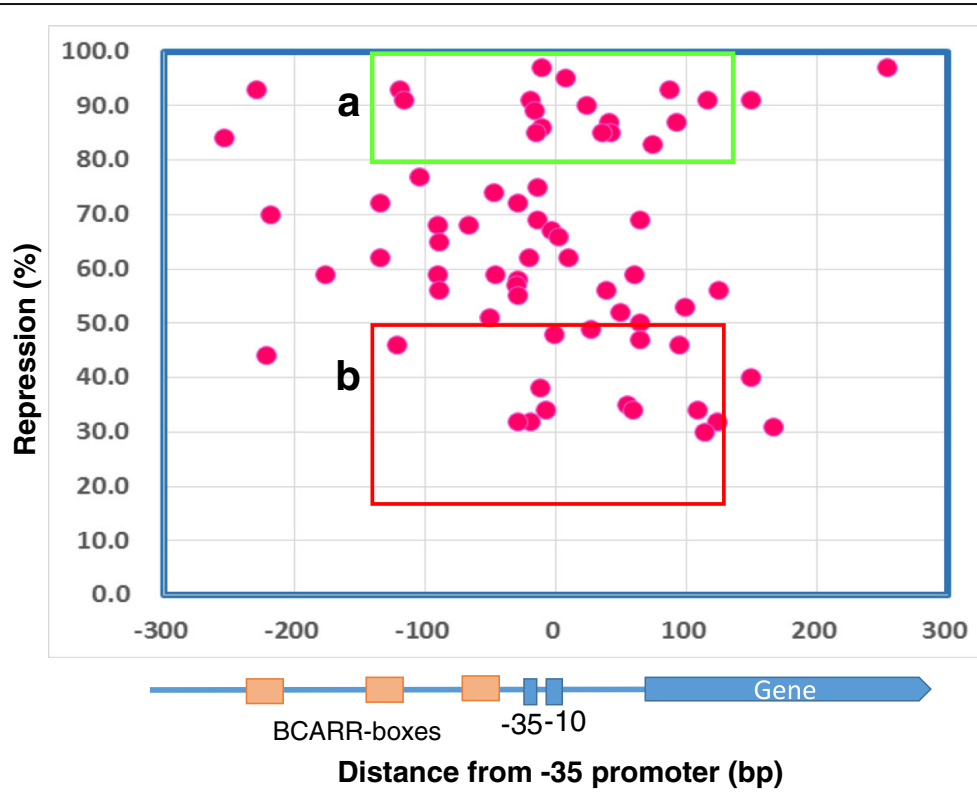

Fig. 5 Location of the predicted BCARR-box in the repressed genes and the repressive effects. The distances from the -35 bp sequence of the promoter (bp) and the repressive effects listed in Table 1 are illustrated in this Fig.. a: A highly repressed motif located -120 to +150 bp from the $-35 \mathrm{bp}$ sequence of the promoter and with repression over $80 \%$ (green box). b: A lowly repressed motif located -120 to $+150 \mathrm{bp}$ from the $-35 \mathrm{bp}$ sequence of the promoter and with repression from 50\% to 30\% (red box) 
Table 2 BCARR-boxes observed in high and low repressive genes in response to peptides

\begin{tabular}{|c|c|c|c|c|c|c|}
\hline $\mathrm{NO}$ & Repression (\%) & ORF No & Gene & BCARR-box sequence & Palindromic pair & $\Delta \mathrm{G}(\mathrm{kcal} / \mathrm{mol})$ \\
\hline \multicolumn{7}{|c|}{$<$ Highly repressed genes $>$} \\
\hline 1 & 91.0 & 1099 & med & GAAAATAATGTTCTT & 4 & 1.15 \\
\hline 2 & 91.0 & 1104 & putative & AAAAAAGCCATTCTT & 5 & -4.2 \\
\hline 3 & 89.0 & 661 & pepD & AAAAATACTTTAATT & 4 & 0.61 \\
\hline 4 & 91.0 & 765 & $\operatorname{himM}$ & AAAAGTATTGTCTIT & 3 & -0.64 \\
\hline 5 & 87.0 & 1621 & putative & AATACAAGATATTGT & 3 & -3.6 \\
\hline 6 & 93.0 & 724 & pepO2 & AAAAAATGCTTITAT & 5 & -0.74 \\
\hline 7 & 84.0 & 1102 & putative & TAAAAAAATATTATT & 4 & 0.94 \\
\hline 8 & 83.0 & 737 & $h p t$ & TGAAAAAGTATTATT & 3 & 0.86 \\
\hline 9 & 93.0 & 726 & potE & AAAAAATCATGTITT & 5 & -0.44 \\
\hline 10 & 91.0 & 769 & putative & AAAAAATCTATTITT & 5 & -2.45 \\
\hline 11 & 93.0 & 1032 & $d d p A$ & AAAATTCTAAAATAT & 4 & 0.18 \\
\hline 12 & 85.0 & 738 & putative & AAAGTAAGCGTITTA & 3 & 1.66 \\
\hline 13 & 87.0 & 1113 & purk & AAAATACCTTGTATT & 4 & -1.05 \\
\hline 14 & 85.0 & 1219 & prtH, prtP & AAATTAAATGTATTT & 5 & 1.71 \\
\hline 15 & 90.0 & 513 & $n / p A$ & AGAAATACAATTATT & 4 & 0.58 \\
\hline 16 & 85.0 & 123 & putative & ACAAAAATTATTCTT & 5 & 0.95 \\
\hline 17 & 86.0 & 670 & putative & AGAAATAGATTITT & 4 & 0.04 \\
\hline 18 & 97.0 & 464 & $d a p F$ & AAAATCACTIIITIA & 4 & 0.17 \\
\hline AV & 88.9 & & & & 4.1 & -0.24 \\
\hline SD & 3.9 & & & & 0.8 & 1.68 \\
\hline \multicolumn{7}{|c|}{$<$ Lowly repressed genes> } \\
\hline 1 & 49.0 & 807 & putative & AACAATAGAATTATA & 4 & 0.67 \\
\hline 2 & 48.0 & 537 & citT & AAAAATAACTTTATT & 4 & 0.26 \\
\hline 3 & 41.0 & 1582 & putative & TAATAAACTGTACTT & 4 & 1.77 \\
\hline 4 & 38.0 & 921 & putative & AAAACATCTITITTG & 4 & 0.25 \\
\hline 5 & 35.0 & 763 & putative & AAAAATGCTTGACTT & 2 & \\
\hline 6 & 34.0 & 825 & putative & ATTAATAGGTITTCT & 3 & 0.95 \\
\hline 7 & 32.0 & 635 & $m d l B, c y d C, \operatorname{sun} T$ & AAAAACACTTTAATT & 4 & 1.26 \\
\hline 8 & 32.0 & 1590 & putative & AAAACAGTITCTTA & 3 & \\
\hline 9 & 27.0 & 745 & pepV & AAAAACAAATTTATT & 4 & -0.04 \\
\hline 10 & 25.0 & 924 & pepO & AAAAAACCTGTTAAC & 2 & 0.86 \\
\hline 11 & 24.0 & 2167 & prtD & AAAAAATCCTTTCTT & 5 & 0.75 \\
\hline 12 & 34.0 & 954 & $d p p D$ & AAAAAAGCTATAAAT & 2 & \\
\hline 13 & 47.0 & 1208 & $h f l C$ & AACAACAGGACTTTA & 2 & 2.14 \\
\hline 14 & 46.0 & 1254 & putative & AAAATAACTATTAAT & 3 & 0.08 \\
\hline 15 & 34.0 & 201 & deoR & AAAAATACATTGTTA & 3 & 0.76 \\
\hline 16 & 32.0 & 1593 & lytR & AAAAAACGTCATATT & 3 & 2.75 \\
\hline 17 & 30.0 & 1535 & putative & AAAAGTAGTTTCAT & 3 & \\
\hline 18 & 46.0 & 1151 & putative & AAAAAATIIITTGT & 5 & -0.56 \\
\hline $\mathrm{AV}$ & 36.3 & & & & 3.3 & 0.85 \\
\hline SD & 8.1 & & & & 1.0 & 0.90 \\
\hline
\end{tabular}



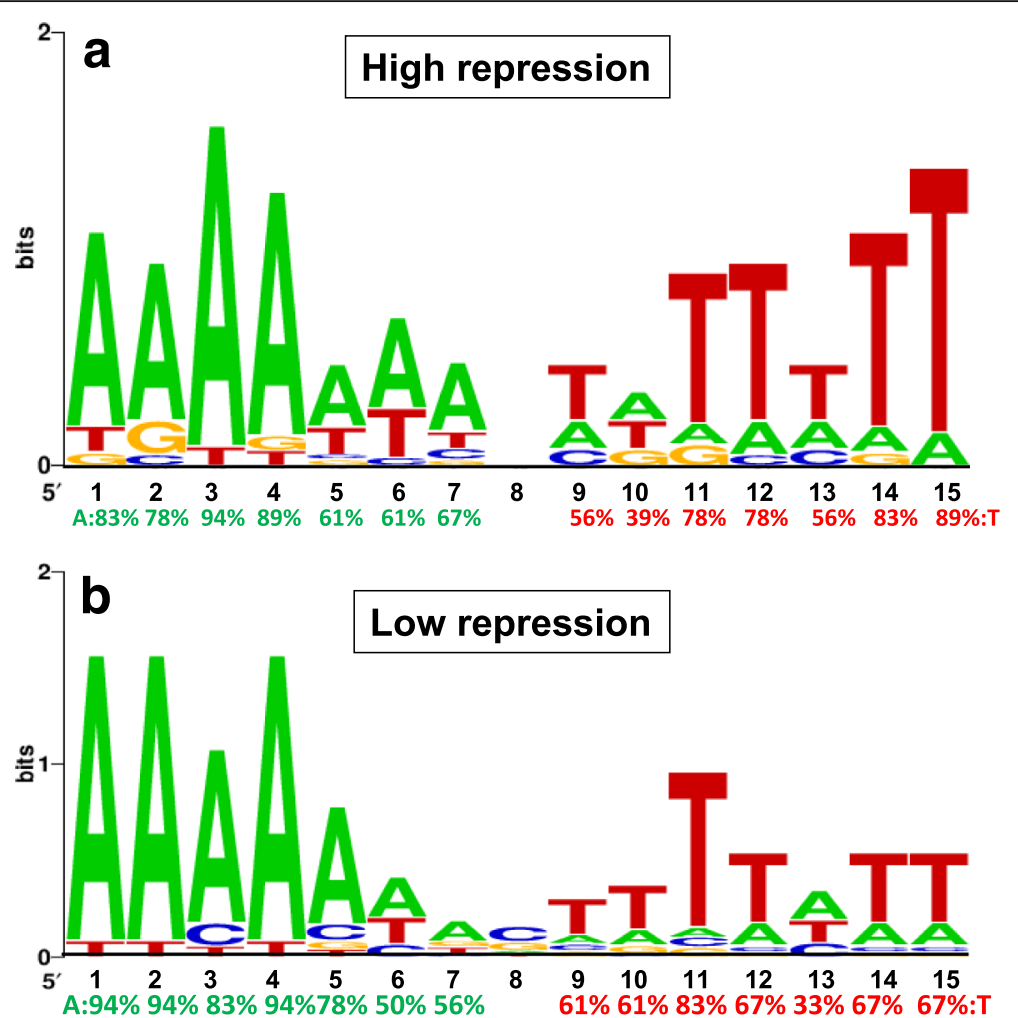

Fig. 6 Search for consensus motifs of BCARR-boxes for highly (a) and lowly (b) repressive groups. The weight matrix shows the frequency of A, C, $\mathrm{T}$ or $\mathrm{G}$ nucleotides (as indicated in the legend) at each position of the motif. The frequencies of $\mathrm{A}$ and $\mathrm{T}$ (\%) are shown in green and red, respectively, below the matrix. A graphical representation of the identified motif was obtained at the Weblogo website (http:// weblogo.berkeley.edu/logo.cgi)

\section{CodY-box in BCARR-box regions}

In lactococci, CodY plays a crucial role in exerting negative regulation on proteolytic gene expressions by binding to the CodY-box in the presence of amino acids. However, no codY gene has been observed in the Lactobacillus genome including that of CM4, and there is no information in the literature about a CodY-box sequence, 5' AATTTTCWGAAAATT-3', in lactobacilli. On the other hand, B. subtilis has both CodY and BCARR genes, suggesting a regulatory system response to BCAAs [14]. So, to investigate the evolutional selection of the regulatory system in lactobacilli, a CodY-box sequence was searched at the promoter regions of 67 genes with BCARR-box sequences in CM4 (Table 1). A CLUSTALW analysis showed that most of the upstream DNA sequences had no CodY-box sequence, however, both the BCARR-box and CodY-box sequences were observed in $\operatorname{deoR}, n l p A$ and $d p p D$ genes and three putative genes at the promoter regions (Fig. 7).

\section{Discussion}

A novel transcriptional regulator protein, BCARR, identified by purification, was found to have an affinity to the upstream regions of six proteolytic genes that were repressed in response to BCAAs in L. helveticus [10]. BCARR is thought to exert downregulation in the proteolytic gene expressions by binding to the BCARR-box, 5'-AAAAANNCTWTTATT-3' in the presence of BCAAs [10]. BCARR, first found in the proteolytic system of L. helveticus, seems to be a global regulator of amino acids metabolism because many gene expressions are broadly repressed by amino acids in CM4 [9]. However, the contribution of BCARR in all repressed gene expressions in the presence of amino acids remains unclear. Various approaches have been introduced in various bacterial gene expressions to study global regulatory genes. Specific DNA sequences for regulatory protein biding have been searched for genome-wide in Escherichia coli [15], Sulfolobus acidophilus [16], Bacillus anthracis [17], Bacillus subtilis [19, 21, 31-34], Clostridium difficile [35], L. lactis [18, 36, 37] and Streptococcus thermophilus [38]. Homologous sequences to the Cre-box sequence were searched for in the whole Bacillus genome and mapped on the genome, and the consensus sequence was newly deduced [33]. Currently, Cre-boxes are classified as high or low affinity sequences depending on the response 


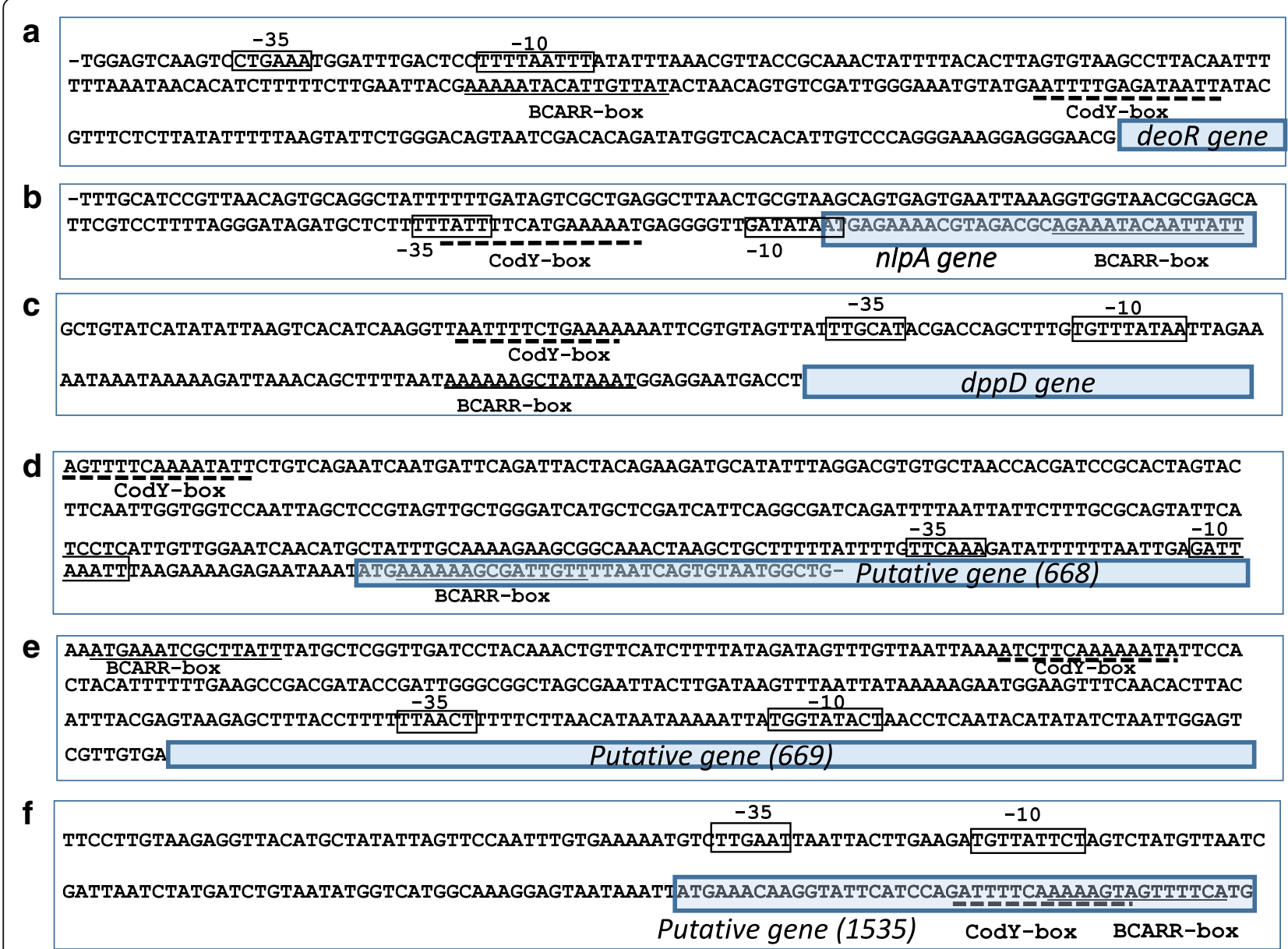

Fig. 7 Both a CodY-box and a BCARR-box in the promoter regions of 6 genes. deoR (a), nlpA (b) and dppD (c) genes and three putative genes with ORF NOs 668 (d), 669 (e) and 1535 (f) are shown. The CodY-box and BCARR-box in the upstream regions of six genes are underlined by dotted and solid lines, respectively. The -35 and -10 bp sequences of the promoter sites are shown in boxes

at low and high levels of CcpAs characterized in $B$. subtilis [33].

A genome-wide analysis of BCARR-boxes was performed to understand the impact of BCARR on specific, 390 down-regulated genes by amino acids. For a more strategic analysis in the present study, BCARRboxes located far from the promoters were considered to be less effective in repressing the gene expressions because BCARR can influence promoter activity by covering the surrounding promoter region ranging over approximately 200 bp of DNA [14]. Therefore, the BCARR-box was searched in the upstream regions from -300 to $+250 \mathrm{bp}$ at the promoter of the 390 down-regulated genes. The BCARR-box search at the promoter regions in the 390 repressed genes based on CLUSTALW analysis, 67 kinds of putative BCARRboxes were found, especially at promoter regions of the proteolytic system, transporters and some transcriptional regulator genes among the 390 repressed genes (Table 1).
Among the predicted 67 genes with BCARR-boxes, 19 genes, shown on the right in Fig. 3 involved in the proteolytic system, amino acid and peptide transport system, transporters with a protease domain, and purine synthesis have a link to amino acid metabolism among the 33 annotated genes (57.5\%) as illustrated in Fig. 3. These cell responses to excess amounts of intracellular amino acids seem to be a catabolite repression-like regulation because there is no need for more amino acid supply via these actions under nutrient-rich conditions. These results revealed that the BCARR system in $L$. helveticus might be the main regulatory system for the proteolytic system and transporters to link to amino acid metabolism as reported for the CodY system in L. lactis [12-14, 36, 37], Bacillus subtilis [11, 34] and Streptococcus thermophilus [38].

The right side of Fig. 3 shows that DapF, involved in L-lysine biosynthesis [39] from L-aspartate, may be controlled to decrease L-lysine production. GuaA and GuaB $[31,40]$ are involved in purine synthesis from IMP to 
GMP with conversion of Gln to Glu. So, BCARR may repress the supply of Glu throughout repressions of guaA and guaB gene expressions in amino acid rich conditions. For genes shown on the left side of Fig. 3, the reason for the repression of the gene expressions remains unclear. Repressions of some transporter genes, such as deoR, lytL and lytR [22, 41], are of interest, which will have a wide impact on many kinds of gene expressions. DeoR $[22,41]$ is present widely in Grampositive and negative bacteria and acts as a repressor in sugar metabolism. The transcriptional regulators LytL and lytR were reported to be linked to alaD gene expression and may be involved in amino acid metabolism, but their role remains unclear. $c y d C[28,42]$, prtD [29] and uup [43] gene products with ATPase activity have been suggested to contribute to membrane control against environmental stress. However, there is no clear evidence to explain a link between amino acid metabolism and these gene products.

To discern the repressive effects of the BCARR, all predicted motifs listed in Table 1 were mapped by location from the promoter and repressive effects (Fig. 5). The different repressive effects were thought to be caused by the location from the promoter, which influences RNA polymerase binding to the promoter, and/or by the preferred structural motif for BCARR. A BCARR-box was most frequently found in regulatory genes adjacent to the -35 sequence of the promoter regions of 67 proteolytic and some transporter genes (Fig. 4). Unexpectedly, the average repressive effects of the gene expressions through a BCARR-box with different locations were similar if the data were collected from a location ranging from -300 to $250 \mathrm{bp}$ from the promoter (Fig. 4). A footprinting analysis in a previous study revealed a wide range of protection of the BCARR-box at the promoter region ranging over $200 \mathrm{bp}$ of DNA by binding of the BCARR in the presence of amino acids [10]. Therefore, the binding of a BCARR to a BCARR-box located between -300 to +250 bp could be sufficient to interfere with the binding of the RNA polymerase to the promoter and repress the following transcription of the corresponding genes.

The structural features of the motif were more important than the location of the promoter because the distances of motifs from promoters did not influence repressive effects. To clarify the influence of the BCARR-box sequence on repressive effects, the structural features of BCARR-box sequences with high (Group A) and low (Group B) repressive effects were compared, and the number of base pairs in the expected palindromic structures was counted (Table 2). The average number of palindromic pairs was significantly higher in Group A $(4.1 \pm 0.8)$ than in Group B
(3.3 \pm 1.0$)$ because of fewer Ts at positions $12(67 \%)$, 13 (33\%), $14(67 \%)$ and $15(67 \%)$ in Group B than in Group A. Moreover, the $\Delta G$ values were significantly lower in Group A $(-0.25 \pm 1.67)$ than in Group B $(0.85 \pm 0.90) \quad(P<0.05)$. These results suggest a more stable palindromic structure in the highly repressive Group A. This idea was also supported by the MEME analysis for all Group A and Group B sequences. The predicted motif for the less effective Group B, 5'A1A2A3A4A5(W)6N7N8N9W10T11(T)12 W13(T)14(T)15-3', showed more variable and fewer Ts at positions 12, 13, 14 and 15 (Fig. 6). These results suggest that a stable palindromic structure might have more frequent BCARR binding. For more precise analysis of the structure preferred by BCARR, a binding assay with purified BCARR toward each motif and a reporter assay involving each BCARR must be performed.

A genome-wide search revealed that higher gene repressions by amino acids might be distributed at some limited loci as shown by I to IV in Fig. 2 in the whole genome, whereas all predicted BCARR-box were distributed evenly in the whole genome in the present study (data not shown). The distributions of the potent repressions at the limited regions may be a more effective system in the acceleration of effective repressions of the neighboring genes. A wide range of unknown regulatory actions by amino acids may be involved in the gene repressions. A comparative analysis between the repressive effects measured like the whole cell response in the present study and a reporter assay containing the corresponding promotor regions may support this suggestion in L. helveticus CM4.

\section{Conclusion}

The genome-wide search for the BCARR-box based on amino acid repressed genes in L. helveticus CM4 revealed frequent involvement in amino acid linked metabolism, such as the proteolytic system, transporter system, and some transcriptional regulator systems. The genes with more stable palindromic structures evaluated by BCARR-box motif analysis were preferable targets for BCARR binding and resulted in higher repressions in the target gene expressions. These results revealed that the BCARR system in L. helveticus might be the regulatory system of amino acid metabolism.

\section{Methods}

\section{Strategic steps of genome-wide analysis}

A transcriptome analysis was performed using CM4 cells collected $0.5 \mathrm{~h}$ after the addition of casein hydrolysate and the cells were compared to those without the peptides in the fermented milk. Genes down-regulated by peptides over $30 \%$ compared to 
control cells cultured without peptides were selected for the analysis of the BCARR-box in the corresponding genes (Step 1). Then, to select specific genes that were repressed by the binding of a BCARR to the BCARR-box, a homolog of the predicted BCARR-box was searched by CLUSTALW and LALIGN analyses in the repressed genes (Step 2). Next, the BCARR-box found in the promoter region of the repressed genes was analyzed for the relationship between the location at the promoter region and the repressive effect (Step $3)$. Then, the palindromic structures of the predicted BCARR-boxes in highly and lowly repressed groups were compared (Step 4).

\section{Bacterial strains and growth conditions}

L. helveticus CM4 with strong extracellular proteinase activity [8] was pre-cultured in $100 \mathrm{ml}$ of $9 \%$ (W/W) low-heated skimmed milk at $37{ }^{\circ} \mathrm{C}$ for $24 \mathrm{~h}$. The precultured fermented milk was added up to $5 \%$ of $1000 \mathrm{ml}$ of fresh medium ( $9 \%$ low-heated skimmed milk). It was fermented at $37{ }^{\circ} \mathrm{C}$ for $25 \mathrm{~h}$ with the $\mathrm{pH}$ maintained at 6.0 by the addition of $50 \% \mathrm{NaOH}$, and the peptone (BD, NJ, USA) was added to the fermented milk up to $2 \%$ at $3 \mathrm{~h}$ after fermentation. For the transcriptome analysis of L. helveticus CM4 in fermented in milk medium with or without peptides, cells were harvested $0.5 \mathrm{~h}$ after the addition of peptone. Harvested cells were added into the same volume of RNA Protect Bacteria Reagent (Qiagen K. K., Tokyo, Japan).

\section{DNA microarray analysis}

DNA microarray experiments were conducted using general protocols. Briefly, cells fermented in the skimmed milk medium with or without peptides were collected by centrifugation at $7000 \mathrm{rpm}$ for $10 \mathrm{~min}$. The cell pellets were quickly freeze in dry ice/ethanol and then stored at $-30{ }^{\circ} \mathrm{C}$ for efficient cell lysis in the following step. Total RNA was extracted using an RNeasy Mini Kit (Qiagen, Valencia, CA) after lysis by lysozyme and phenol treatments. Total RNA was purified and used for a quality analysis. Untreated cells were used as controls. The microarray analysis was performed according to the protocol of Roche NimbleGen, Inc. (Madison, WI). A microarray for $L$. helveticus CM4 genes was prepared based on the whole genome sequence (unpublished sequence, but a related study was reported in ref. [20]) and was used in this study. cDNA was synthesized from total RNA for use in the hybridization. The hybridized arrays were scanned and normalized using NimbleScan software. The results for specific genes are presented as an $\mathrm{n}$-fold change of expression. We selected genes if they were down-regulated less than $30 \%$ in a comparison of cells cultured with or without peptides.

\section{Additional file}

Additional file 1: Table S1. Repressed gene expressions over 30\% by adding peptides (amino acids) in CM4 (XLS 71 kb)

\section{Abbreviations}

BCAAs: Branched chain amino acids; BCARR: Branched-chain amino acid responsive repressor; BCARR-box: Branched chain amino acid responsive repressor protein binding box; CodY-box: CodY protein binding box

\section{Acknowledgements}

We are grateful to Mr. Tadashi Shinoda for his assistance in data analysis and critical reading.

\section{Funding}

N/A

\section{Availability of data and materials}

We show data relevant for the present study obtained in our laboratory in the Additional file 1: Table S1. The datasets used in the current study are available from the corresponding author on the reasonable request.

\section{Authors' contributions}

NY conceptualized the study. TW performed experiments. NY analyzed the data, visualized and drafted the manuscript. All authors discussed the results and commented on the manuscript. Both authors read and approved the final manuscript.

Ethics approval and consent to participate

Not applicable.

\section{Consent for publication}

Not applicable.

\section{Competing interests}

The authors declare that they have no competing interests.

\section{Publisher's Note}

Springer Nature remains neutral with regard to jurisdictional claims in published maps and institutional affiliations.

\section{Author details}

${ }^{1}$ School of Life Science and Technology, Tokyo Institute of Technology, 4259-J3-8, Nagatsuta-cho, Midori-ku, Yokohama, Kanagawa 226-8501, Japan. ${ }^{2}$ Research and Development Center, Asahi Group Holdings Ltd., 11-10, 5-chome, Fuchinobe, Chuo-ku, Sagamihara-shi, Kanagawa 252-0206, Japan. ${ }^{3}$ Core Technology laboratories, Asahi Group Holdings Ltd., 11-10, 5-chome, Fuchinobe, Chuo-ku, Sagamihara-shi, Kanagawa 252-0206, Japan.

Received: 27 August 2017 Accepted: 15 November 2017

Published online: 02 December 2017

\section{References}

1. Guedon E, Serror P, Ehrlich SD, Renault P, Delorme C. Pleiotropic transcriptional repressor CodY senses the intracellular pool of branchedchain amino acids in Lactococcus lactis. Mol Microbiol. 2001;40(5):1227-39.

2. Yamamoto N, Akino A, Takano T, Shishido K. Presence of active and inactive molecules of a cell wall-associated proteinase in Lactobacillus helveticus CP790. Appl Environ Microbiol. 1995;61(2):698-701.

3. Yamamoto N, Akino A, Takano T. Antihypertensive effect of different kinds of fermented milk in spontaneously hypertensive rats. Biosci Biotechnol Biochem. 1994:58(4):776-8.

4. Nakamura Y, Yamamoto N, Sakai K, Okubo A, Yamazaki S, Takano T. Purification and characterization of angiotensin I-converting enzyme inhibitors from sour milk. J Dairy Sci. 1995;78(4):777-83. 
5. Nakamura Y, Yamamoto N, Sakai K, Takano T. Antihypertensive effect of sour milk and peptides isolated from it that are inhibitors to angiotensin Iconverting enzyme. J Dairy Sci. 1995;78(6):1253-7.

6. Yamamoto N, Maeno M, Takano T. Purification and characterization of an antihypertensive peptide from a yogurt-like product fermented by Lactobacillus helveticus CPN4. J Dairy Sci. 1999;82(7):1388-93.

7. Yamamoto N. Antihypertensive metabolites from lactic acid bacteria. Lactic Acid Bacteria and Bifidobacteria. Norwich, U.K: Caister Academic Press; 2011. p. pp223-32.

8. Yamamoto N, Ishida Y, Kawakami N, Yada H. Lactobacillus helveticus bacterium having high capability of producing tripeptide, fermented milk product, and process for preparing the same. EU Patent, 1991; 1016709A1.

9. Wakai T, Hatanaka M, Nakamura Y, Yamamoto N. Repressive processing of antihypertensive peptides, Val-pro-pro and Ile-pro-pro in Lactobacillus helveticus fermented milk by added peptides. J Biosci Bioeng. 2012;144:133-7.

10. Wakai T, Yamamoto N. A novel branched chain amino acids responsive transcriptional regulator, BCARR, negatively acts on the proteolytic system in Lactobacillus helveticus. PLoS One 2013; 8 (10) :e75976.

11. Barbieri G, Albertini AM, Ferrari E, Sonenshein AL, Belitsky BR. Interplay of CodY and scoC in the regulation of major extracellular protease genes of Bacillus subtilis. J Bacteriol. 2016;198(6):907-20.

12. den Hengst CD, van Hijum SA, Geurts JM, Nauta A, Kok J, Kuipers OP. The Lactococcus lactis CodY regulon: identification of a conserved cis-regulatory element. J Biol Chem. 2005;280(40):34332-42.

13. Belitsky BR, Sonenshein AL. Genetic and biochemical analysis of codYbinding sites in Bacillus subtilis. J Bacteriol. 2008;190(4):1224-36.

14. Petranovic D, Guédon E, Sperandio B, Delorme C, Ehrlich D, Renault P. Intracellular effectors regulating the activity of the Lactococcus lactis CodY pleiotropic transcription regulator. Mol Microbiol. 2004;53(2):613-21.

15. Pilalis E, Chatziioannou AA, Grigoroudis Al, Panagiotidis CA, Kolisis FN, Kyriakidis DA. Escherichia coli genome-wide promoter analysis: identification of additional AtoC binding target elements. BMC Genomics. 2011;12(1):238.

16. Liu H, Wang K, Lindås AC, Peeters $E$. The genome-scale DNA-binding profile of BarR, a $\beta$-alanine responsive transcription factor in the archaeon Sulfolobus acidocaldarius. BMC Genomics. 2016;17:569.

17. Château A, van Schaik W, Joseph P, Handke LD, McBride SM, Smeets FM, Sonenshein AL, Fouet A. Identification of CodY targets in Bacillus anthracis by genome-wide in vitro binding analysis. J Bacteriol. 2013;195(6):1204-13.

18. Ercan O, Wels M, Smid EJ, Kleerebezem M. Genome-wide transcriptional responses to carbon starvation in nongrowing Lactococcus lactis. Appl Environ Microbiol. 2015;81(17):2554-61.

19. Prestel $E$, Noirot $P$, Auger $S$. Genome-wide identification of Bacillus subtilis Zur-binding sites associated with a Zur box expands its known regulatory network. BMC Microbiol. 2015:15:13.

20. Wakai T, Shinoda T, Uchida N, Hattori M, Nakamura Y, Beresford T, Ross RP, Yamamoto N. Comparative analysis of proteolytic enzymes need for processing of antihypertensive peptides between Lactobacillus helveticus CM4 and DPC4571. J Biosci Bioeng. 2013;115(3):246-52.

21. Miwa Y, Nakata A, Ogiwara A, Yamamoto M, Fujita Y. Evaluation and characterization of catabolite-responsive elements (cre) of Bacillus subtilis. Nucleic Acids Res. 2000;28(5):1206-10.

22. Nikolskaya AN, Galperin MY. A novel type of conserved DNA-binding domain in the transcriptional regulators of the AlgR/AgrA/LytR family. Nucleic Acids Res 2002; 30 (11): 2453-2459.

23. Elgrably-Weiss M, Schlosser-Silverman E, Rosenshine I, Altuvia S. DeoT, a DeoR-type transcriptional regulator of multiple target genes. FEMS Microbiol Lett. 2006:254(1):141-8.

24. Serizawa M, Kodama K, Yamamoto H, Kobayashi K, Ogasawara N, Sekiguch J. Functional analysis of the $\mathrm{YvrGHb}$ two-component system of Bacillus subtilis: identification of the regulated genes by DNA microarray and northern blot analyses. Biosci Biotechnol Biochem. 2005;69(11):2155-69.

25. Paik SH, Chakicherla A, Hansen JN. Identification and characterization of the structural and transporter genes for, and the chemical and biological properties of, sublancin 168, a novel lantibiotic produced by Bacillus subtilis 168. J Biol Chem. 1998;273(36):23134-42.

26. Allikmets $\mathrm{R}$, Gerrard B, Court D, Dean M. Cloning and organization of the $a b c$ and $m d l$ genes of Escherichia coli: relationship to eukaryotic multidrug resistance. Gene. 1993;136(1-2):231-6.

27. Cheng HC, Muhlrad PJ, Hoyt MA, Echols H. Cleavage of the cll protein of phage $\mathrm{k}$ by purified HfIA protease: control of the switch between lysis and lysogeny. PNAS. 1988;85(21):7882-6.
28. Poole RK, Hatch L, Cleeter MW, Gibson F, Cox GB, Cytochrome WG. Bd biosynthesis in Escherichia coli: the sequences of the $c y d C$ and $c y d D$ genes suggest that they encode the components of an $A B C$ membrane transporter. Mol Microbiol. 1993;10(2):421-30.

29. Delepelaire P. PrtD, the integral membrane ATP-binding cassette component of the Erwinia chrysanthemi metalloprotease secretion system, exhibits a secretion signal-regulated ATPase activity. J Biol Chem. 1994; 269(45):27952-7.

30. Yamamoto H, Murata M, Sekiguchi J. The CitST two-component system regulates the expression of the mg-citrate transporter in Bacillus subtilis. Mol Microbiol. 2000;37(4):898-912.

31. Bringel F, Hammann P, Kugler V, Arsène-Ploetze F. Lactobacillus plantarum response to inorganic carbon concentrations: PyrR2-dependent and -independent transcription regulation of genes involved in arginine and nucleotide metabolism. Microbiology. 2008;154(Pt9):2629-40.

32. Fujita Y. Carbon catabolite control of the metabolic network in Bacillus subtilis. Biosci Biotechnol Biochem. 2009;73(2):245-59.

33. Marciniak BC, Pabijaniak $M$, de Jong A, Dühring $R$, Seidel G, Hillen W, Kuipers OP. High- and low-affinity cre boxes for CcpA binding in Bacillus subtilis revealed by genome-wide analysis. BMC Genomics. 2012;13:401.

34. Wray LV Jr, Fisher SH. Bacillus subtilis CodY operators contain overlapping CodY binding sites. J Bacteriol 2011; 193 (18): 4841-4848.

35. Antunes A, Camiade E, Monot M, Courtois E, Barbut F, Sernova NV, Rodionov DA, Martin-Verstraete I, Dupuy B. Global transcriptional control by glucose and carbon regulator CcpA in Clostridium difficile. Nucleic Acids Res. 2012;40(21):10701-18

36. den Hengst CD, Groeneveld M, Kuipers OP, Kok J. Identification and functional characterization of the Lactococcus lactis CodY-regulated branched-chain amino acid permease BcaP (CtrA). J Bacteriol. 2006;188(9):3280-9.

37. Ercan O, Wels M, Smid EJ, Kleerebezem M. Genome-wide transcriptional responses to carbon starvation in non growing Lactococcus lactis. Appl Environ Microbiol. 2015;81:2554-61.

38. WW L, Wang Y, Wang T, Kong J. The global regulator CodY in Streptococcus thermophilus controls the metabolic network for escalating growth in the milk environment. Appl Environ Microbiol. 2015;81(7):2349-58.

39. Hartmann M, Tauch A, Eggeling L, Bathe B, Möckel B, Pühler A, Kalinowski J. Identification and characterization of the last two unknown genes, dapC and dapF, in the succinylase branch of the L-lysine biosynthesis of Corynebacterium glutamicum. J Biotechnol. 2003;104(1-3):199-211.

40. Saxild HH, Nygaard P. Regulation of levels of purine biosynthetic enzymes in Bacillus subtilis: effects of changing purine nucleotide pools. J Gen Microbiol. 1991;137(10):2387-94.

41. Amouyal M, Mortensen L, Buc H, Hammer K. Single and double loop formation when deoR repressor binds to its natural operator sites. Cell. 1989;58(3):545-51.

42. Holyoake LV, Hunt S, Sanguinetti G, Cook GM, Howard MJ, Rowe ML, Poole RK, Shepherd M. CydDC-mediated reductant export in Escherichia coli controls the transcriptional wiring of energy metabolism and combats nitrosative stress. Biochem J. 2016;73(6):693-701.

43. Murat D, Goncalves L, Dassa E. Deletion of the Escherichia coli uup gene encoding a protein of the ATP binding cassette superfamily affects bacterial competitiveness. Res Microbiol. 2008;159(9-10):671-7.

\section{Submit your next manuscript to BioMed Central and we will help you at every step:}

- We accept pre-submission inquiries

- Our selector tool helps you to find the most relevant journal

- We provide round the clock customer support

- Convenient online submission

- Thorough peer review

- Inclusion in PubMed and all major indexing services

- Maximum visibility for your research

Submit your manuscript at www.biomedcentral.com/submit 